\title{
Chiral Fluorescence Recognition by Anthracene Fluorescent Dyes $\subset$ Water-Soluble Pillar[5]arene Containing Phosphonic Acid Group (PWP[5])
}

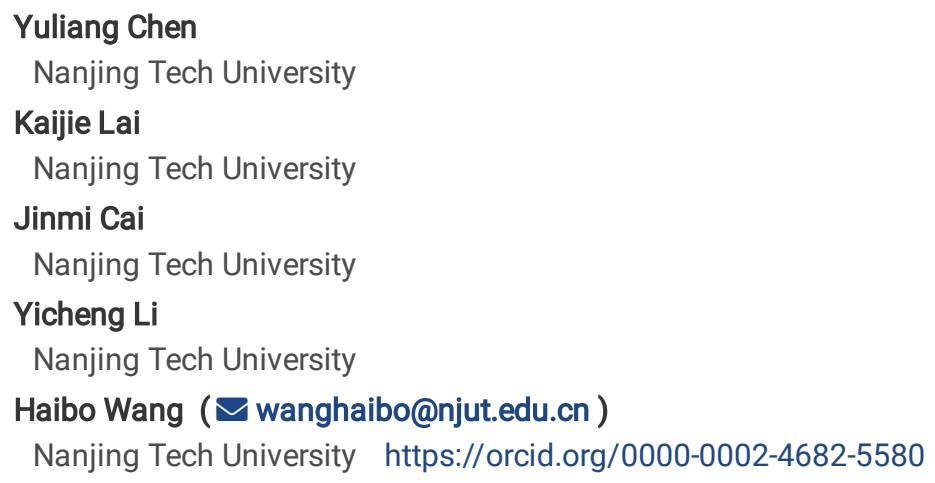

\section{Research Article}

Keywords: Chiral recognition, AD, PWP[5], Assembly

Posted Date: December 9th, 2021

DOI: https://doi.org/10.21203/rs.3.rs-1092454/v1

License: @ (1) This work is licensed under a Creative Commons Attribution 4.0 International License. Read Full License

Version of Record: A version of this preprint was published at Journal of Fluorescence on March 1st, 2022. See the published version at https://doi.org/10.1007/s10895-022-02908-3. 


\section{Abstract}

Chirality plays a pivotal role in drugs, agrochmeicals and food additives et al. The enantiomers of a chiral molecule often show huge difference in bioactivity, metabolism, and toxicity et al. thereby, the recognition of chiral molecules shows an increasingly important priority, and has become an important focus and frontier in medicine, biochemistry and other fields. In this paper, a novel method for chiral fluorescence recognition based on anthracene fluorescent dyes(AD) $\subset$ water-soluble pillar[5] arene containing phosphonic acid group(PWP[5]) is developed. The AD as guest molecule can complex with PWP[5] to form 1:1 AD $\subset$ PWP[5] assembly, and this assembly can be further used as a fluorescent probe to identify $\mathrm{D} / \mathrm{L}$-phenylalanine and $\mathrm{D} / \mathrm{L}$-phenylalaninol by fluorescent titration. The fluorescence intensity of the assembly was significantly reduced for D-phenylalanine and D-phenylalaninol, while L-phenylalanine or L-phenylalaninol was added to AD $\subset$ PWP[5] assembly, the fluorescence intensity of the assembly almost unchanged. Hence, the chiral recognition based on assembly between the achiral fused ring fluorescent dye and achiral PWP[5] was developed.

\section{Introduction}

Chirality means that an object cannot coincide with its mirror image, such as the relationship between our left and right hands [1] . Chiral molecules not only play an important role in medicine. biochemistry and agrochemistry et al.[2], they are also widely applied in asymmetric organocatalysis, molecular recognition, and material functionalization. A pair of enantiomers have different pharmacological activities[3]. Rthalidomide can alleviate pregnancy reaction, thus, S-thalidomide not only has antiemetic effect, but also has severe teratogenic effect[4].Dpenicillamine has strong toxicity and potential carcinogenicity, and L-penicillamine has antiviral activity. L-phenylalanine区Fig.1囚is an essential amino acids for humans and animals, and has broad physiological activity. As raw material it can be used in synthesis of antiviral and anticancer drugs and sweeteners. D-phenylalanine can enhance human immunity and shows an excellent analgesic effect.

Pillar(n)arenes as the 5th generation macrocyclic host after crown ethers[5],cyclodextrins[6],calixarene[7] and Cucurbituril[8] were first reported by Ogoshi[9] in 2008, and synthesized by condensation of hydroquinone ethers and paraformaldehyde with Lewis acid as a catalyst.

Compared with other macrocyclic hosts, they have higher symmetry and rigidity, and high binding selectivity to the guest. Modification of pillar(n)arenes at two ports with different substituents can provide assembling diversity, and adjust lipophilic/hydrophilic properties to realize assembling in organic solvents or water.

At present, the traditional method of chiral recognition include HPLC [10], CE [11], GC [12], CD [13] et al. However, these methods have some shortcomings and cannot meet the requirements of real-time, in-situ detection and high-quality screening in drug development.

So far, there are few reports about fluorescence chiral recognition based on assembly. Previously, our group has studied the cis/trans and chiral fluorescence recognition by NA $\subset \mathrm{CB}[7]$ assembly [14-15]. On this basis, in order to enhance stability of binary assembly and the $\pi-\pi$ interaction in recognizing process, PWP[5] as a substitute of $\mathrm{CB}[7] \rrbracket$ and anthracene dye as a substitute of naphthalimide dye『we further studied characteristics of the achiral AD $\subset$ achiral PWP[5] to hope to achieve better selectivity and sensitivity in fluorescence recognition of chiral molecules. In this paper, the assembly of AD $\subset$ PWP[5] was constructed and characterized by fluorescence titration and ${ }^{1} H N M R$. The results showed that $A D$ can be included by PWP[5] with 1:1 stoichiometry and fluorescence intensity decreased 10 times. When Dphenylalanine or D-phenylalaninol was added to the AD $\subset$ PWP[5], the fluorescence intensity of the assembly further reduced $60 \%$ and $65 \%$, while L-phenylalanine or L-phenylalaninol was added to AD $\subset$ PWP[5], the fluorescence intensity of the AD $\subset$ PWP[5] assembly almost unchanged. Thereby, a new method to recognize chiral substances based on AD $\subset$ PWP[5] was developed.

\section{Experiment}

\section{Materials and Methods}

The absorption spectra were determined by Agilent Cary $60 \mathrm{UV}$-spectrophotometer. The fluorescence titration spectra were measured on Perkin Elmer Is-55 fluorescence spectrophotometer. The excitation and emission slits were set at $3 \mathrm{~nm}$ and $5 \mathrm{~nm} .{ }^{1} \mathrm{H}$ NMR spectra were recorded on Bruker 400M spectrometer. Tetramethyl silane (TMS) was used as internal reference.

D/L-phenylalanine and D/L-phenylalaninol used in the experiment were purchased from Aladdin Biochemical Technology Co., Ltd.

PWP[5] was synthesized according to the method provided in the literature[16], AD was synthesized from anthracene. and the other reagents could be purchased and used directly. 
Synthesis of 9-anthracene formaldehyde: (Fig.2) Anthracene (4 g, $22.4 \mathrm{mmol})$ was dissolved in a mixture of $4.4 \mathrm{~mL}$ of DMF and $5 \mathrm{~mL}$ of 1,2dichlorobenzene, to the mixture $\mathrm{POCl}_{3}(6 \mathrm{~mL}, 65.3 \mathrm{mmol})$ was added under stirring. The solution was then heated at $100^{\circ} \mathrm{C}$ for $2 \mathrm{~h}$, and $\mathrm{cooled}$ down to $0^{\circ} \mathrm{C}$, saturated sodium acetate solution was added until pH 5-6, and stirred at r.t. for 10 minutes , extracted with $\mathrm{DCM}$. The organic phase was evaporated under reduced pressure and then triturated with hexane, a yellow solid was obtained (1.5 g, $32 \%)$. ${ }^{1} \mathrm{H} \mathrm{NMR} \mathrm{(400} \mathrm{MHz}$, $\left.\mathrm{CDCl}_{3}-\mathrm{d}_{6}\right): \delta=10.00(\mathrm{~s}, 1 \mathrm{H}), 8.91-8.86(\mathrm{~d}, 2 \mathrm{H}), 8.83-8.74(\mathrm{~d}, 1 \mathrm{H}), 8.10-7.99(\mathrm{~d}, 2 \mathrm{H}), 7.69-7.52(\mathrm{~d}, 4 \mathrm{H})$.

The synthesis method steps of AD: (Fig. 2) To mixture of 9-anthracene aldehyde $(5.0 \mathrm{~g}, 24.20 \mathrm{mmol})$ in ethanol (10 mL), hexamethylene diamine $12.13 \mathrm{~mL}(121.00 \mathrm{mmol})$ was added slowly at r.t.. After stirring overnight, sodium borohydride $\nabla 7.0 \mathrm{~g}, 185 \mathrm{mmol} \varangle \mathrm{was}$ added and heated to $50^{\circ} \mathrm{C}$ for $2 \mathrm{~h}$. Cooled, water $(100 \mathrm{~mL})$ was added and extracted with dichloromethane $(100 \mathrm{~mL})$, dried, and concentrated under reduced pressure to give AD. (yellow solid, 2.07g, 93\%). ${ }^{1} \mathrm{H}$ NMR $\left.\left(400 \mathrm{MHz}, \mathrm{DMSO}-\mathrm{d}_{6}\right): \delta=8.54 \llbracket \mathrm{s}, 1 \mathrm{H}\right), 8.42-8.40(\mathrm{~d}, 2 \mathrm{H}), 8.09-8.07(\mathrm{~d}, 2 \mathrm{H}), 7.56-$ $7.50(\mathrm{q}, 4 \mathrm{H}), 4.64(\mathrm{~s}, 1 \mathrm{H}), 2.78-2.73(\mathrm{q}, 4 \mathrm{H}), 1.49(\mathrm{~s}, 1 \mathrm{H}), 1.29-1.24(\mathrm{~d}, 2 \mathrm{H})$.

${ }^{13} \mathrm{CNMR}\left(101 \mathrm{MHz}, \mathrm{DMSOd}_{6}\right): \delta=131.33,131.15,129.49,127.49,125.00,40.58,40.37,40.16,39.95,39.74,39.53,39.32,38.94,27.15,26.12,25.90,25.79$

Synthesis of 1a: (Fig.5)1,4-Dibromoethoxybenzene $(2.0 \mathrm{~g}, 6.0 \mathrm{mmol})$ and trioxymethylene $(0.55 \mathrm{~g}, 6.0 \mathrm{mmol})$ were dissolved in dichloromethane $(200 \mathrm{~mL})$ and stirred at $25^{\circ} \mathrm{C}$ for $30 \mathrm{~min}$. Then Boron trifluoride etherate $(0.9 \mathrm{~g}, 6.0 \mathrm{mmol})$ was added to the solution and the mixture was stirred at $25^{\circ} \mathrm{C}$ for $72 \mathrm{~h}$. Hydrochloric acid solution $(1.0 \mathrm{~mol} / \mathrm{L}, 20 \mathrm{~mL})$ was added to quenching the reaction, then the mixture was washed with water $(2 \times 50 \mathrm{~mL})$ and dried over $\mathrm{Na}_{2} \mathrm{SO}_{4}$. Concentration provided a crude product, purification by column chromatography, using petroleum ether/dichloromethane $(1: 1, \mathrm{v} / \mathrm{v})$ as eluent afforded $1 \mathrm{a}(1.0 \mathrm{~g}, 50 \%) .{ }^{1} \mathrm{H} \mathrm{NMR}\left(400 \mathrm{MHz}, \mathrm{CDCl}_{3}-\mathrm{d}_{6}\right): \delta=6.90$ $(\mathrm{s}, 10 \mathrm{H}), 4.22(\mathrm{t}, \mathrm{q}, 2 \mathrm{H}), 3.84(\mathrm{~s}, 10 \mathrm{H}), 3.62(\mathrm{t}, \mathrm{q}, 20 \mathrm{H})$.

Synthesis of $1 \mathrm{~b}$ : (Fig. 5) The mixture of $1 \mathrm{a}(0.8 \mathrm{~g}, 0.5 \mathrm{mmol})$ and triethyl phosphite $(8.24 \mathrm{~g}, 50 \mathrm{mmol})$ were stirred at $165^{\circ} \mathrm{C}$ for $24 \mathrm{~h}$ under nitrogen atmosphere. Then, the crude product was subjected to silica gel chromatography using methanol/ethyl acetate (1:2, v/v) as eluent, and the target $1 \mathrm{~b}$ was obtained as a light yellow oil $(1 \mathrm{~g}, 0.41 \mathrm{mmol}, 89 \%) .{ }^{1} \mathrm{H} \mathrm{NMR}\left(400 \mathrm{MHz}, \mathrm{CDCl}_{3}-\mathrm{d}_{6}\right): \delta=6.86(\mathrm{~s}, 10 \mathrm{H}), 4.22-4.09(\mathrm{~m}, 20 \mathrm{H})$, $3.50-3.93(\mathrm{~m}, 70 \mathrm{H}), 2.33-2.44(\mathrm{~m}, 20 \mathrm{H})$.

Synthesis of $1 \mathrm{c}$ :(Fig.5) $\mathrm{TMSBr}(4.75 \mathrm{~g}, 31.03 \mathrm{mmol})$ was added to a solution of $1 \mathrm{~b}(1.0 \mathrm{~g}, 0.45 \mathrm{mmol})$ in dichloromethane $(15 \mathrm{~mL})$ at $0^{\circ} \mathrm{C}$ under nitrogen atmosphere. The mixture was then allowed to warm to $25^{\circ} \mathrm{C}$ and stirred for $24 \mathrm{~h}$. The solvent was removed under reduced pressure, and water $(10 \mathrm{~mL})$ was added and stirred for $30 \mathrm{~min}$. Then the water was removed under reduced pressure, The residue was titrated with acetone to afford $1 \mathrm{c}$ as a white solid $(0.6 \mathrm{~g}, 1 \mathrm{mmol}, 78 \%)$.

${ }^{1} \mathrm{HNMR}\left(400 \mathrm{MHz}, \mathrm{DMSO}-\mathrm{d}_{6}\right): \delta=6.88(\mathrm{~s}, 10 \mathrm{H}), 4.10-4.05(\mathrm{t}, 2 \mathrm{H}), 3.68(\mathrm{~s}, 10 \mathrm{H}) 2.27-2.22(\mathrm{t}, 2 \mathrm{HH})\left(\right.$ Fig.6) ${ }^{31} \mathrm{P} \mathrm{NMR}\left(162 \mathrm{MHz}, \mathrm{DMSO}-\mathrm{d}_{6}\right): \delta=22(\mathrm{Fig} .7)$

${ }^{13} \mathrm{CNMR}\left(101 \mathrm{MHz}, \mathrm{DMSO}-\mathrm{d}_{6}\right), \delta=149.32,127.93,114.28,63.14,29.76$.

Synthesis of (PWP[5]):(Fig.5) 1c (100 mg, $0.059 \mathrm{mmol})$ and $\mathrm{NaOH}(23.6 \mathrm{mg}, 0.59 \mathrm{mmol})$ were added to $\mathrm{H}_{2} \mathrm{O}(10 \mathrm{~mL})$ and stirred at $25^{\circ} \mathrm{C}$ for $12 \mathrm{~h}$. Water was then removed, and the PWP[5] was obtained as a light yellow solid (112.7 mg, $0.059 \mathrm{mmol}, 100 \%)$.

\section{Results And Discussion}

\section{Formation of AD $\subset$ PWP[5] Assembly}

The binding behaviors of AD $\subset$ PWP[5] was characterized by fluorescence and UV-Vis spectroscopy. AD (concentration is $6 \times 10^{-5} \mathrm{~mol} / \mathrm{L}$ ) was titrated by different concentration of PWP[5] solution( $\left.0 \sim 9 \times 10^{-5} \mathrm{~mol} / \mathrm{L}\right)$, and its fluorescence curves (Fig.9a) and inclusion constant (Fig.10) were obtained, respectively. With the increase of PWP[5], the emission wavelength changes from $498 \mathrm{~nm}$ to $495 \mathrm{~nm}$, and the fluorescence intensity decreased about 6 times. From Fig.9b, red shift of the absorption wavelength from 375 to $395 \mathrm{~nm}$ appeared, this phenomenon indicated an interaction between PWP[5] and AD. The fluorescence emission mechanism of anthracene dye AD belongs to intramolecular charge transfer (ICT), that is, the charge is transferred from the aminohexyl chain to the anthracene ring in the molecule. When NA was titrated with PWP[5], the aminohexyl group of AD was encapsulated by the cavity of PWP[5], which blocked electron transfer from amino chain to anthracene ring, led to fluorescence decrease. When the concentration of AD was equal to that of PWP[5] , the fluorescence intensity decreased to minimum, Even if more PWP[5] was added, the fluorescence intensity almost unchanged, which indicates that AD and PWP[5] form a 1:1 complex. (Fig. 9).

Here we define $\Delta \mathrm{F}$ by $\Delta \mathrm{F}=\mathrm{F}-\mathrm{F}_{0}$. Where $\mathrm{F}$ represented the fluorescence intensity of PWP[5] at different concentrations of $\mathrm{PWP}[5]$, and $\mathrm{F}_{0}$ was the fluorescence intensity of the guest (AD) solution. Figure 10 showed the relationship between 1/ $\Delta F$ and 1/PWP[5]. The ratio of the intercept of the regression line to the slope gave the inclusion constant $\mathrm{K}_{\mathrm{AD} \subset \mathrm{PWP}[5]}=2.05 \times 10^{5} \mathrm{~L} / \mathrm{mol}$, indicating that a more stable inclusion 
compound is formed. (Compared with the previously studied NA $\subset \mathrm{CB}[7]$ assembly, the inclusion constant is increased about 4 times.

$\left.\mathrm{K}_{\mathrm{NACCB}[7]}=4.94 \times 10^{4} \mathrm{~mol} / \mathrm{L}[15].\right)$

In order to further confirmed AD $\subset$ PWP[5], the ${ }^{1} \mathrm{HNMR}$ was performed. As shown in Figure 11, in the presence of PWP[5], the signal of the guest $A D$ proton exhibited higher field shifts $(\Delta \delta=-0.10,-0.15,-0.12,-0.21,-0.19$, and -0.10 ppm for protons a,b,c,d,e,f $)$.

At the same time, due to the deshielding effect, the proton peaks in anthracene shifted down field $(\Delta \delta=0.31,0.10,0.12,0.13,0.13$ and $0.1 \mathrm{ppm}$ for protons of $10,1,2,4,6$ and8,respectively). These results indicate that the aminoalkyl side chain of AD penetrates into the cavity of PWP[5].

\section{Fluorescent Recognition of D/L-phenylalanine and D/L-phenylalaninol by AD $\subset$ PWP[5]}

A concentration of $6 \times 10^{-5} \mathrm{~mol} / \mathrm{L}$ solution of AD $\subset$ PWP[5] was titrated by different concentration $\left(0 \sim 9 \times 10^{-5} \mathrm{~mol} / \mathrm{L}\right)$ of $\mathrm{D} / \mathrm{L}$-phenylalanine, fluorescence spectra had been measured and recorded. $6 \times 10^{-5} \mathrm{~mol} / \mathrm{L}$ of AD $\subset \mathrm{PWP}[5]$ solution and $0 \sim 9 \times 10^{-5} \mathrm{~mol} / \mathrm{L}$ of $\mathrm{D} / \mathrm{L}-$ phenylalanine were mixed, as shown in Fig.12b , with the addition of different concentrations of L-phenylalanine solution to the AD $\subset$ PWP[5] assembly, the emission wavelength and fluorescence intensity almost unchanged. However, when different concentrations of Dphenylalanine were added to AD $\subset$ PWP[5] , the fluorescence intensity decreased about 2.5 times. (Fig.12a) at the same time, blue shift of emission wavelength from $504 \mathrm{~nm}$ to $500 \mathrm{~nm}$ appeared.

Therefore, ADCPWP[5] was able to recognize the enantiomers of D/L-phenylalanine. We supposed that in the process of hydrogen bond formation between the hydrogen of the amino and carboxyl groups in D-phenylalanine and phosphonic acid group in the port of PWP[5] (Fig.14), AD $\subset$ PWP[5] assembly could induce the benzene ring and anthracene ring to be parallel, thereby, a stable $\pi-\pi$ interaction appeared, which led to the fluorescence decrease. However, L-phenylalanine was different from D-phenylalanine in the spatial configuration, the assembly could not induce the parallel between benzene ring and anthracene ring and a stable $\pi-\pi$ interaction could not occur, so the fluorescence almost unchanged.

The same titration was also performed to D/Lphenylalaninol solution, as shown in Fig. 13. When D - phenylalaninol was added to AD $\subset$ PWP[5], the fluorescence intensity decreased by about 2.7 times, and the emission wavelength shifted from $504 \mathrm{~nm}$ to $498 \mathrm{~nm}$ (Fig. $13 \mathrm{a}$ ). For $\mathrm{L}$-phenylalanine, the emission wavelength and fluorescence intensity almost unchanged (Fig. 13b). The recognition mechanism of D/Lphenylalaninol is similar to that of D/L-phenylalanine.

\section{Conclusions}

In summary, the assembly based on AD $\subset$ PWP[5] had been successfully applied to the recognition of chiral molecule.

$A D \subset P W P[5]$ assembly was constructed and characterized by fluorescent titration and ${ }^{1} \mathrm{HNMR}$ with $1: 1$ ratio and $\mathrm{K}$ AD $\subset \mathrm{PWP}[5]=2.05 \times 10^{5}$ $\mathrm{mol} / \mathrm{L}$. The AD $\subset$ PWP[5] assembly was used as fluorescent probe to recognized D/L-phenylalanine and D/L-phenylalaninol, When assembly was titrated by D-phenylalanine or D-phenylalaninol, a stable $\pi-\pi$ interaction occurred which led to the fluorescence decrease, and for L-phenylalanine or L-phenylalaninol, a stable $\pi-\pi$ interaction could not occur, so fluorescence intensity almost not changed.

In a words, we have successfully recognized D/L-phenylalanine,D/L-phenylalanine by AD $\subset$ PWP[5].Thus we have provided a new method to recognize chiral molecule.

\section{Declarations}

Acknowledgements The author would like to thank the College of chemistry and molecular engineering of Nanjing Tech University for the instrumental assistance provided.

Authors'Contribution YC, KL, YL, and JC completed all experimental work. YC analyzed the results and writed papers, HB proposed concepts, designd assemble model ideas, and provided supervision and completed review.

Funding The research was conducted under the facilities of College of chemistry and molecular engineering, Nanjing Tech University, and no special financial support is required.

Data Availability Statement Data sharing does not apply to this article Because no database was generated or analyzed during the current research period.

Ethics Approval Not applicable. 
Consent to Participate Not applicable.

Consent for Publication Not applicable.

Conflict of Interest There is no confict to declare.

\section{References}

1. Ueshima R, Asami T Single-Gene speciation by left-right reversal [J].Nature.2003, 425 (6959),679-679. https://doi.org/10.1038/425679a

2. Govan J, Gun'Ko YK (2016) Recent progress in chiral inorganic nanostructures[J]. https://doi.org/10.1039/9781782623717-00001

3. Randová A (2015) Sorption of enantiomers and alcohols into Nafion and the role of air humidity in the experimental data evaluation[J]. Separation\&Purification Technology 144:232-239. https://doi.org/10.1016/j.seppur.2015.02.045

4. Li-Li B, Ma-Lin LI (2008) Research progress of the anti-tumor mechanism and clinical application of thalidomide[J]. Chinese Journal of Drug Application and Monitoring

5. Pedersen CJ The discovery of crown ethers (noble lecture).Angew ChemIntEd.2010, 27:10211027https://doi.org/10.1002/anie.198810211

6. Iwanaga T, Nakamoto R, Yasutake M et al (2006) Cyclophanes within Cyclophanes: The Synthesis of a Pyromellitic Diimide-Based Macrocycle as a Structural Unit in a Molecular Tube and Its Inclusion Phenomena[J]. Angew Chem Int Ed. https://doi.org/10.1002/anie.200504499

7. Volker Böhmer. Calixarenes, Macrocycles with (Almost) Unlimited Possibilities[J].Angewandte Chemie International Edition,2010, 34(7):713-745. https://doi.org/10.1002/anie.199507131

8. Liu YH, Zhang YM, Yu HJ et al (2020) Cucurbituril-Based Biomacromolecular Assemblies[J]. Angew Chem Int Ed. https://doi.org/10.1002/anie.202009797

9. Ogoshi T, Kanai S, Fujinami S et al (2008) para-Bridged symmetrical pillar[5]arenes: their Lewis acid catalyzed synthesis and host-guest property.[J]. J Am Chem Soc 130(15):5022-5023. https://doi.org/10.1021/ja711260m

10. István Ilisz, Berkecz R, Antal P (2008) Application of chiral derivatizing agents in the high-performance liquid chromatographic separation of amino acid enantiomers: A review[J]. J Pharm Biomed Anal 47(1):1-15. https://doi.org/10.1016/j.jpba.2007.12.013

11. Desiderio C, Fanali S (1998) Chiral analysis by capillary electrophoresis using antibiotics as chiral selector[J]. From Journal of Chromatography A 818(2):281-282. https://doi.org/10.1016/S0021-9673(98)00061-2

12. SchurigV (2002) Practice and theory of enantioselective complexation gas chromatography[J]. J Chromatogr A 965(1-2):315-356. https://doi.org/10.1016/S0021-9673(01)01500-X

13. Tang Q et al (2019) Deviations from Beer's law in electronic absorption and circular dichroism: Detection for enantiomeric excess analysis.Chirality, 31(7) p.492-501. https://doi.org/10.1002/chir.23072

14. Pan Q, He Z, Xia D et al Fluorescent Determination of Succinylcholine Chloride by Naphthalimide/ Stilbazolium Dye $\subset$ CP5A[J].Journal of Fluorescence.2018, 28(2),581-587. https://doi.org/10.1007/s10895-018-2219-2

15. Chen X, Hu N, Wei H et al (2020) Chiral Fluorescent Recognition by Naphthalimide[J]. J Fluoresc 30(3):679-685. https://doi.org/10.1007/s10895-020-02539-6

16. Hu XY, Liu X, Zhang W et al Controllable Construction of Biocompatible Supramolecular Micelles and Vesicles by Water-Soluble Phosphate Pillar[5,6]arenes for Selective Anti Cancer Drug Delivery[J].Chemistry of Materials,2016:acs.chemmater. 6b00691.https://pubs.acs.org/doi/10.1021/acs.chemmater.6b00691

\section{Figures}




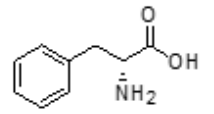

D-phenylalanine

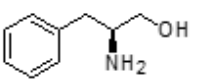

D-phenylalaninol

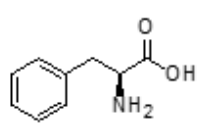

L-phenylalanine

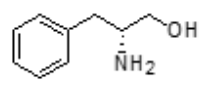

L-phenylalaninol

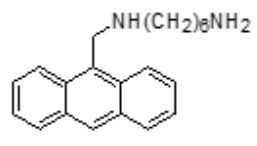

$\mathrm{AD}$

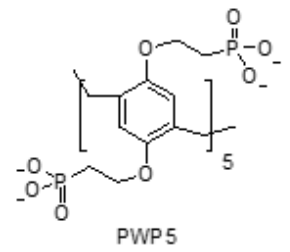

Figure 1

Structures of D/L-phenylalanine, D/L-phenylalaninol, PWP[5] and AD

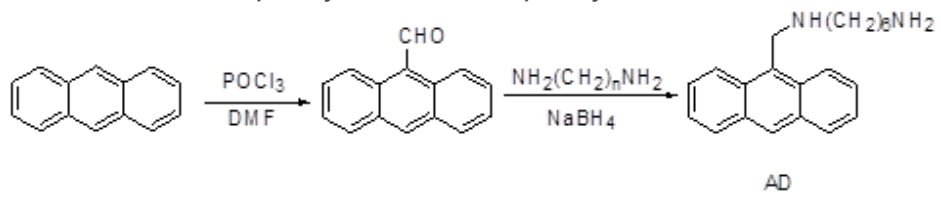

Figure 2

Synthesis of $A D$

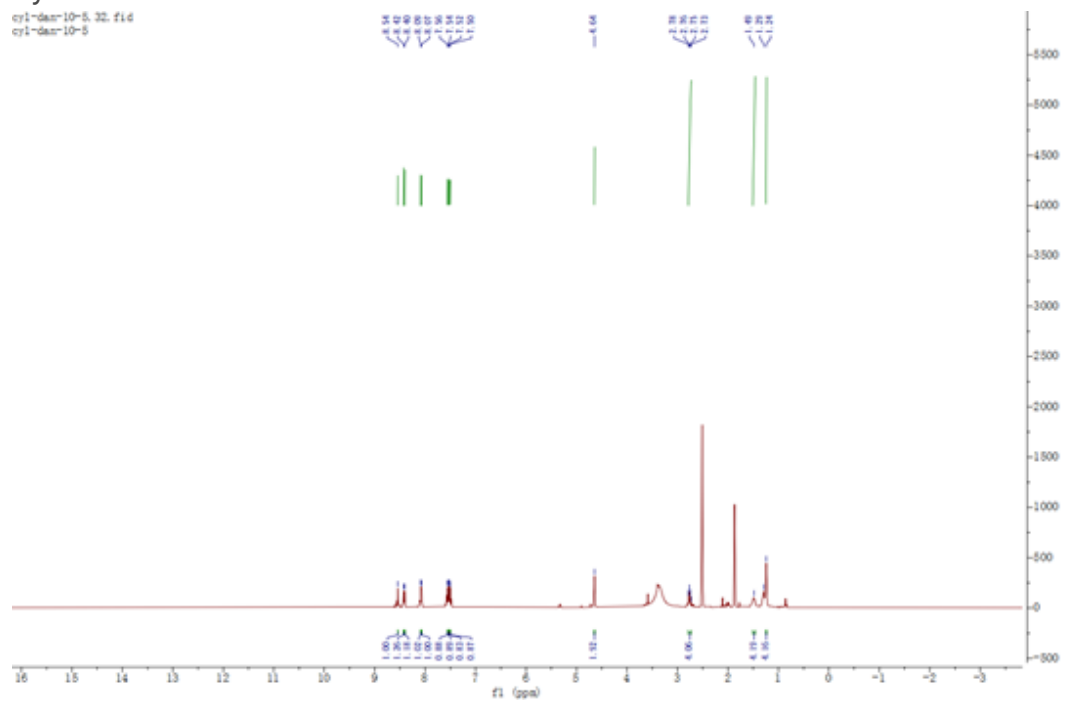

Figure 3

1HNMR spectrum of $A D$ 


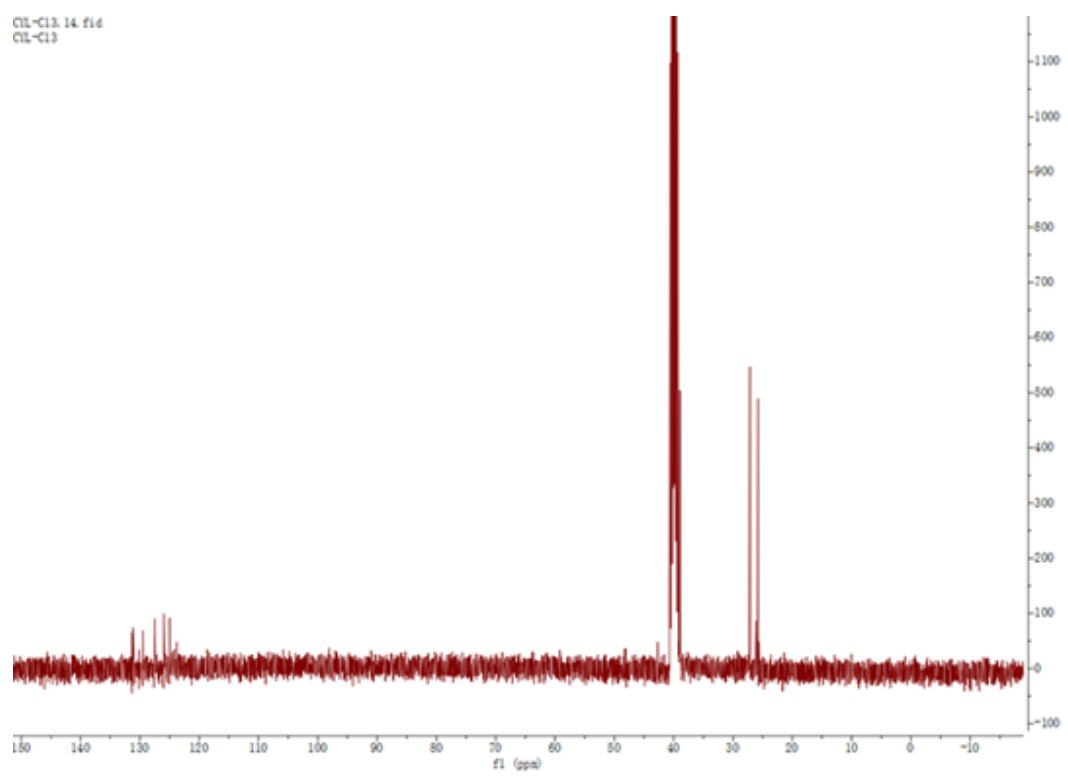

Figure 4

13CNMR spectrum of $A D$
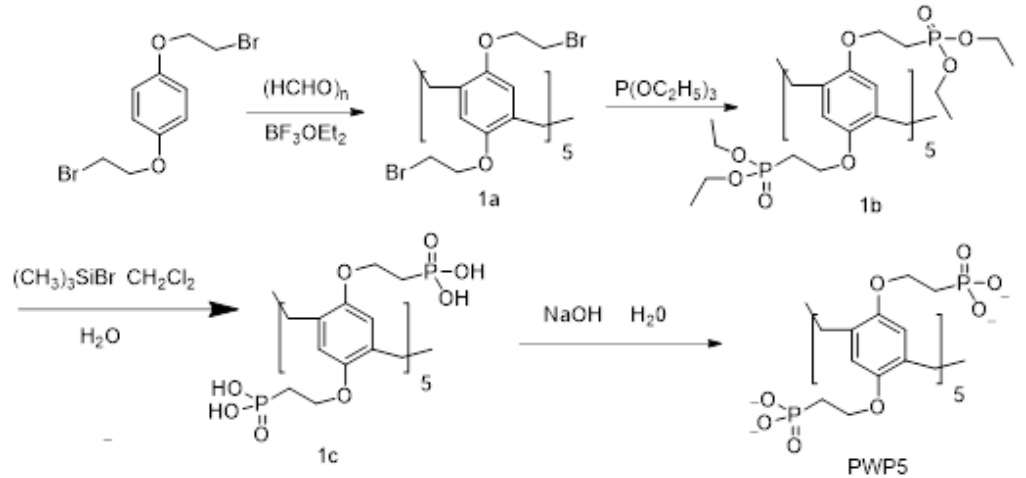

Figure 5

Synthesis of PWP[5]

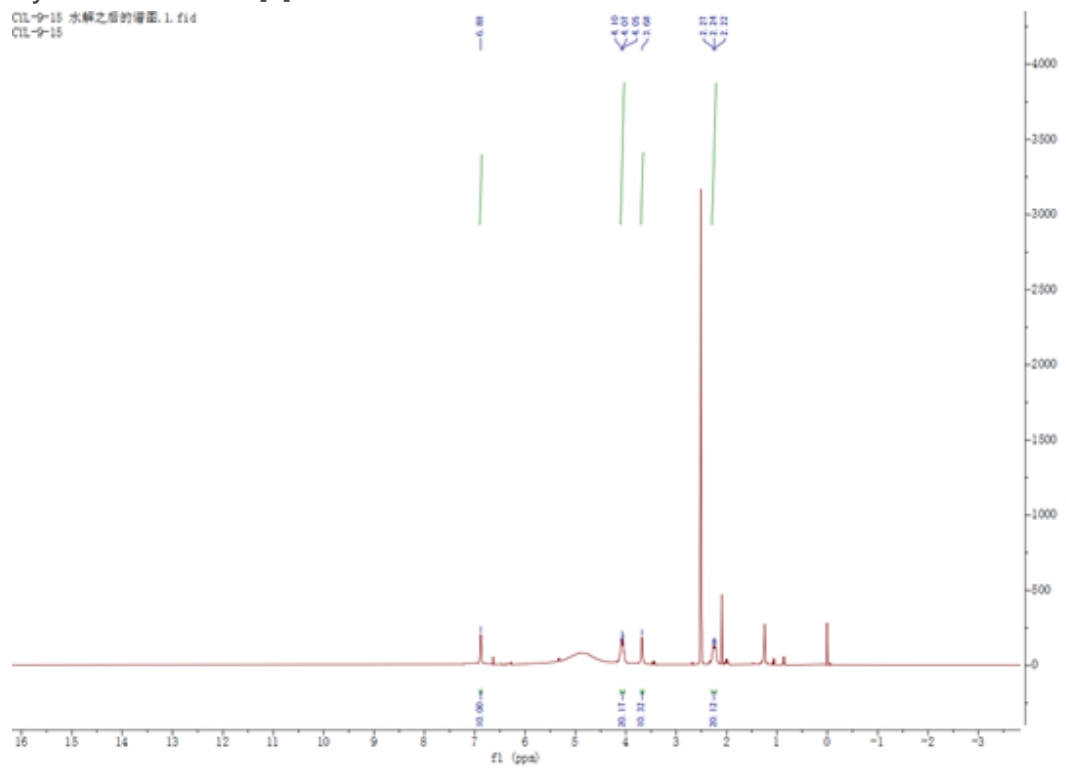

Figure 6 


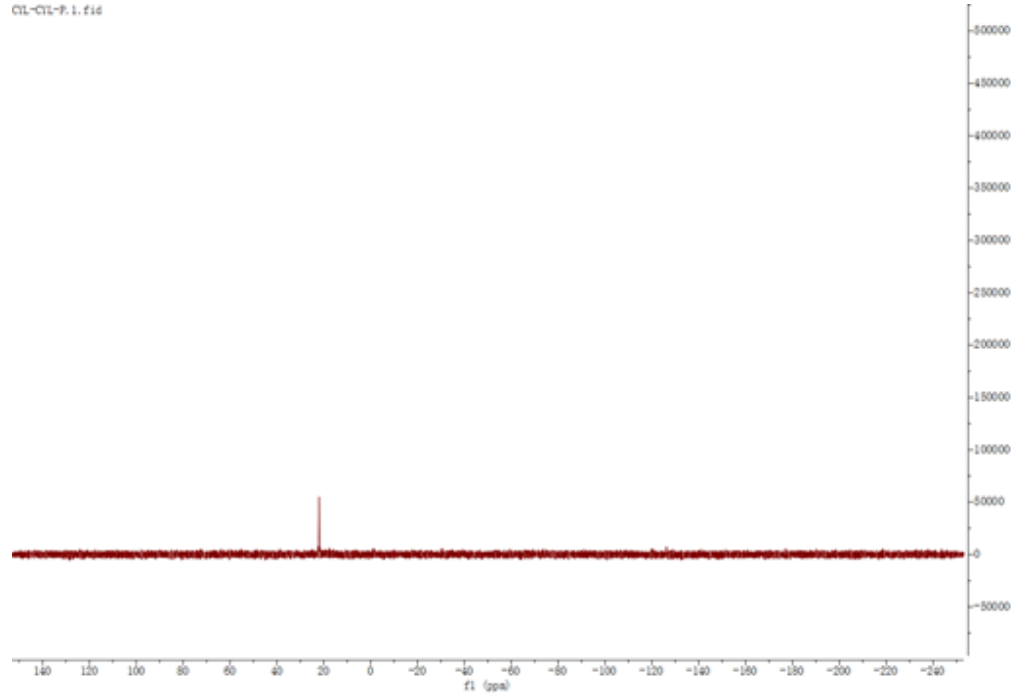

\section{Figure 7}

31PNMR spectrum of $1 \mathrm{c}$ cht-c-101010.20. fid

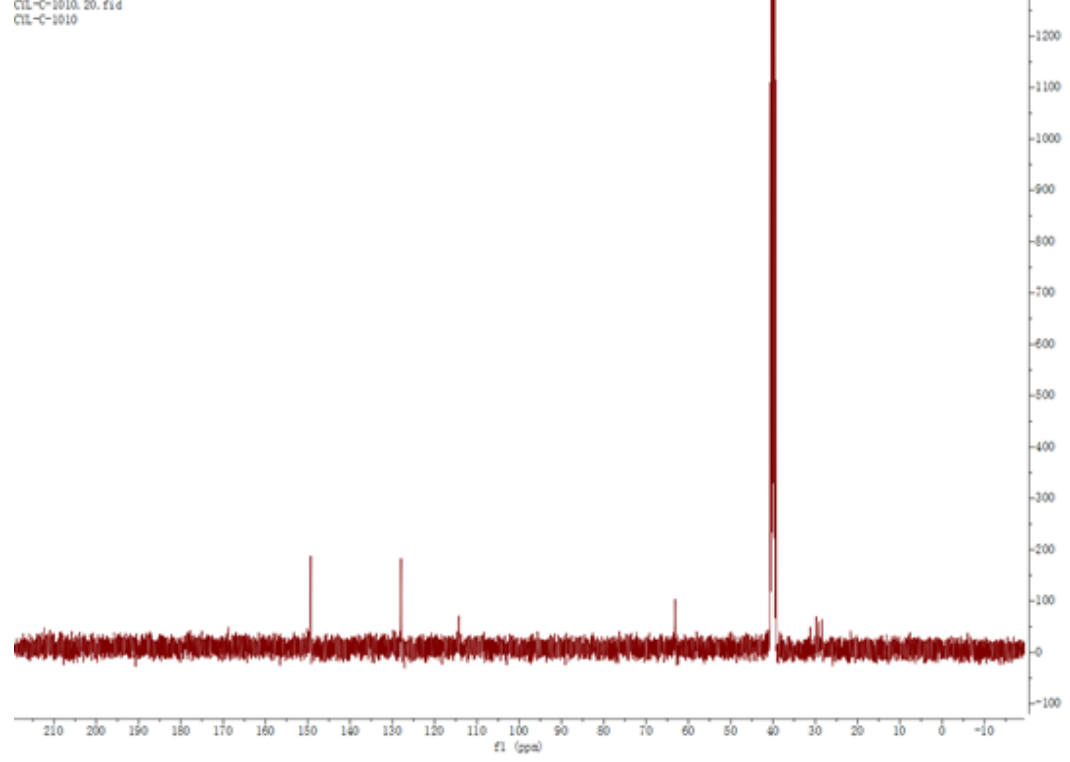

\section{Figure 8}

13CNMR spectrum of $1 \mathrm{c}$
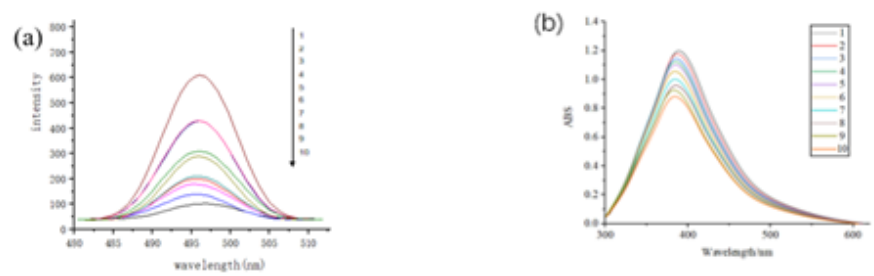

\section{Figure 9}

Fluorescence (a) and absorption(b) spectra of AD (6×10-5mol/L) titrated by different concentration of PWP[5]( $\times 10-5 \mathrm{~mol} / \mathrm{L}):(1)$; (2) $1 ;$ (3) 2 ; (4) 3 ; (5) 4; (6) 5; (7) 6; (8) 7; (9) 8; (10) 9 in aqueous solution 


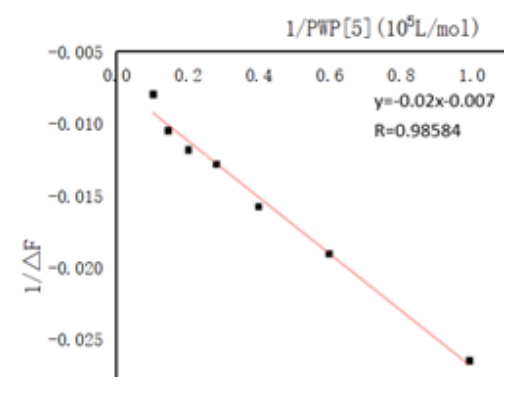

\section{Figure 10}

Inclusion constant of AD $\subset$ PWP[5]

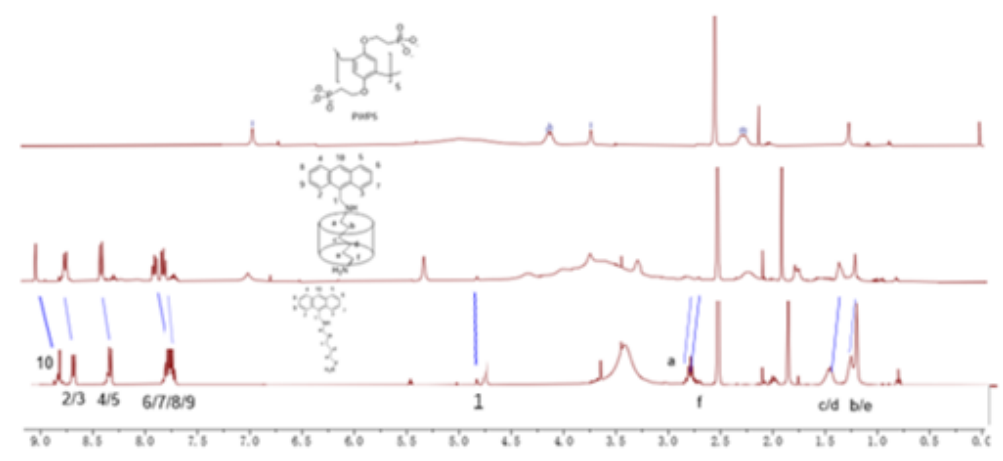

Figure 11

1HNMR spectrum of AD before and upon addition of Pillar[5] arene: (A) PWP[5], (B) ADCPWP[5], (C)AD
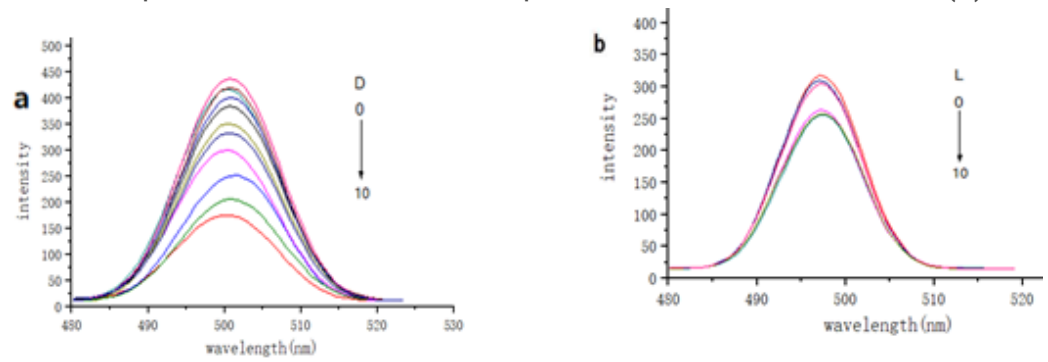

Figure 12

Fluorescence spectra of AD $\subset$ PWP[5] (6×10-5mol/L) titrated by different concentration of D-phenylalanine (a) and L-phenylalanine (b) $(\times 10-5 \mathrm{~mol} / \mathrm{L}):(0) 0$; (1) 1 ; (2) 2; (3) 3; (4) 4; (5) 5; (6) 6; (7) 7; (8) 8; (9);9
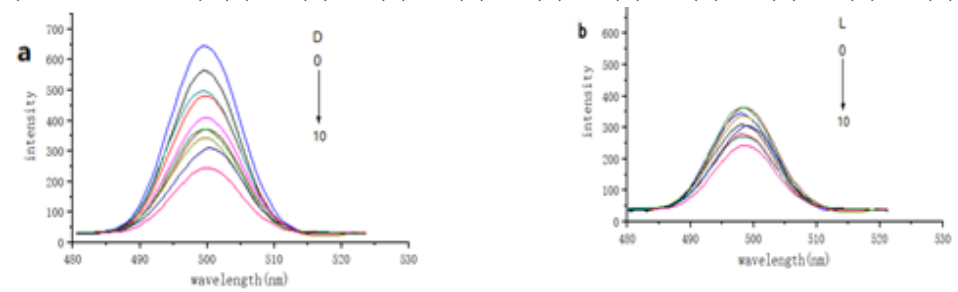

\section{Figure 13}

Fluorescence spectra of AD $\subset$ PWP $[5](6 \times 10-5 \mathrm{~mol} / \mathrm{L})$ titrated by different concentration of D-phenylalaninol(a) and L-phenylalaninol (b) $(\times 10-5 \mathrm{~mol} / \mathrm{L}):(0) 0$; (1) 1 ; (2) 2; (3) 3; (4) 4; (5) 5; (6) 6; (7) 7; (8) 8; (9) 9 


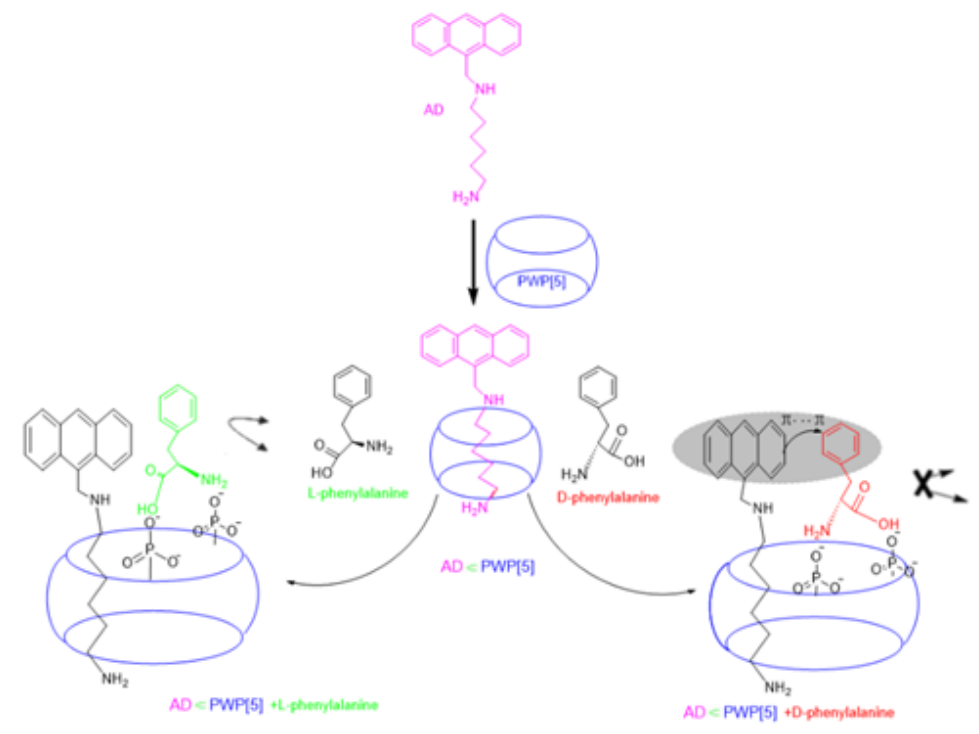

Figure 14

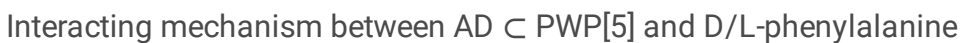

